priate an equal sum. In the first year the sum of $\$ 200,000$ is for administration and investigation, $\$ 500,000$ for training teachers for vocational work, and $\$ 1,000,000$ for payment of teachers, equally divided between agriculture, on the one side, and trade, home economics and industry, on the other.

Of special interest to scientific men is the Newlands bill establishing research stations in engineering, corresponding to the existing agricultural stations in the colleges of agriculture and the mechanic arts. These land grant colleges and their agricultural research stations have been of incalculable value to education, to agriculture, to the states and to the nation. They have been largely responsible for the establishment and development of the state universities. The land grant colleges and the institutions of which they are a part received in 1914 from the United States \$2,500,000 ; from the states and from other sources over $\$ 30,000,000$. They have 9,000 instructors and 105,000 students.

By the Hatch act of 1887 and the Adams act of 1906 the sum of $\$ 30,000$ a year is appropriated for research in agriculture in the experiment stations. The colleges have more students of mechanic arts than of agriculture, but there is no similar provision for research in the mechanic arts and engineering, and the sciences, such as physics and chemistry, on which they are based. The agricultural interests have always had great influence on legislation and in this case they have led the way. It is to be hoped that research in the engineering sciences will now be equally encouraged by the passage of the Newlands bill, which appropriate $\$ 15,000$ to each state and territory for conducting investigations in engineering and publishing the results.

Some scientific men may believe that more could be accomplished by the establishment of one great research laboratory or by granting the money only to institutions already distinguished for their contributions to science. There is, however, much to be said for initiating investigation in fifty widely scattered centers where work is already being done in agricultural science. It brings the value of research to the attention of the students of the college and the people of the state, and each station has the possibility of great development. In any case the passage of the bill as it stands is the most feasible method at present to extend research and will forward rather than interfere with other methods.-The Scientific Monthly.

\section{SCIENTIFIC BOOKS}

The Mathematical Theory of Probabilities. By Arne Fisher, F.S.S. Translated and edited from the author's original Danish notes with the assistance of WiLLIAM BonYNGe, B.A., with an introductory note by F. W. Frankland, F.I.A., F.A.S., F.S.S. New York, The Macmillan Company. Vol. I. Pp. ix +171 .

Although a considerable number of standard text-books on probability have appeared in recent years in foreign languages, there is a lack of such books in the English language. Both on this account and because of the selection of subject-matter, the present book should be particularly useful. Research work in the theory of probability has received during the past twenty years a new impetus, through the labors of certain mathematical statisticians. In this connection, we may perhaps mention particularly the work of Pearson in England, Lexis in Germany, Westergaard in Denmark. Each group of investigators seems to have moved along its particular line. In the present work an attempt is made to treat these researches from a common point of view based on the mathematical principles grounded in the work of Laplace, "Theorie analytique des Probabilites."

The introductory chapter consists of a brief discussion of the general principles and philosophical aspects of a theory of probability. Here, in the determination of what events are to be regarded as "equally likely," both the principle of "insufficient reason" and the principle of " cogent reason" are illustrated, and the inference is drawn that a compromise of the two principles gives us a valuable meaning of "equally likely." Then follow some interesting historical and biographical notes. 
The definition of mathematical probability from which are developed the elementary theorems of probability is quoted from Czuber, and is about the usual definition of a priori probability. The author is rather emphatic in his criticism of the idea of replacing the a priori probabilities of Laplace by the empirical ratios of Mill, Venn and Chrystal. He believes the distrust of a priori probabilities is due to a misapprehension of the true nature of Bernoulli's theorem, which is the cornerstone of the theory of statistics. The chapter on probability a posteriori deals with the criticisms of Bayes's rule in a rather constructive manner, by indicating the limitations under which Bayes's rule will give correct results in practise. The author makes the connection between a priori probabilities and statistical series by the use of the well-known theorem of Tchebycheff. In this connection he offers a proof that the limit of a relative frequency $\alpha / s$ when $s$ becomes infinite is the postulated $a$ priori probability $p$. It seems to the reviewer that the notion of limit here employed is not quite the rigorous notion; for, the statement that the probability that $|\alpha / s-p|<\delta$ approached 1 as a limit, is not the same as the usual statement that $|a / s-p|$ becomes and remains less than $\delta$. The author does not seem to discriminate in this connection between a point of condensation and a limit point.

One of the most interesting and important parts of this book is its neat and striking applications of Bernoulli, Poisson and Lexis series to the characterization of actual data. Furthermore, the application of the Lexian ratio and of the Charlier coefficient of disturbancy is clearly shown. Taken as a whole, this book will be found of much value to students of the mathematical methods in statistics.

\section{H. L. RIETZ}

Gould's Practitioner's Medical Dictionary. Third edition, revised and edited by R. J. E. Scotr, M.A., B.C.L., M.D., of New York. Pp. $\mathrm{xx}+962$. Flexible cloth, round corners, marbled edges. P. Blakiston's Son \& Co., Philadelphia. Price $\$ 2.75$.
The history of medical dictionaries begins with the fifteenth century. The first works of the kind are the "Synonyma" (Venice, 1473) of Simone de Cordo or Simon of Genoa and the contemporary Pandects of Mathæus Silvaticus. Both these works are alphabetical lists of medicinal simples, but a goodly number of real medical dictionaries were published during the Renaissance period, in particular those of Lorenz Fries or Phryesen (1519), Henri Estienne or Stephanus (1564) and Jean de Gorris (1564).

In the seventeenth century appeared the famous "Lexica" of Bartholommeo Castelli (1607) and Steven Blancard (1679) which passed through many editions. After these the number of medical dictionaries is legion. Among the best known of more recent times are those of Robert James (London, 1743) and P. H. Nysten (Paris, 1810), which, in 1855, was entirely rewritten by Emile Littré and Charles Robin and is still a standard source of reference. In England, the dictionary of the New Sydenham Society (1878-99), in America that of Frank P. Foster (1888-93), and in France, Galtier-Boissière's "Larousse Médical illustré" (1912), are monuments of scholarship. Gould's large illustrated medical dictionary (1894), frequently revised and reedited, has been of great practical use to the medical profession. Of late years the tendency has been towards handy volumes of reasonable thickness, printed on thin paper, with flexible covers, and of these the new edition of Gould's Practitioner's Dictionary is an excellent example.

This new edition is unsurpassed as to comprehensiveness, clearness and size. It contains over 70,000 words. To reduce the size of the book and to make it a handy volume a small type had to be selected, but the type is very clear and legible and is even a little larger than that used in Webster's Unabridged Dictionary. Each word is accompanied by its pronunciation and followed by its etymology. The definitions are clear and concise.

The book contains all the numerous and latest eponyms in their proper alphabetical order, such as Abderhalden's test, Alzheimer's disease, Lane's kink, Meltzer's method, 